\title{
Carbon dioxide snow cleaning of paper
}

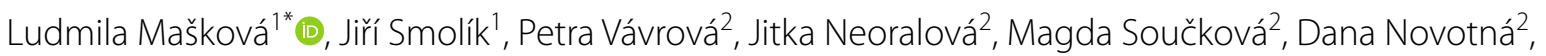 \\ Věra Jandová1, Jakub Ondráček', Lucie Ondráčková', Tereza Kř́žzová2, Kateřina Kocová ${ }^{2}$ and Petr Stanovský ${ }^{1}$
}

\begin{abstract}
The cleaning of particles from smooth and rough paper surfaces using a high-speed $\mathrm{CO}_{2}$ snow jet was investigated. The measurements included characterization of the jet properties, determination of the cleaning efficiency, and evaluation of any possible adverse effects. The method was compared with nitrogen jet cleaning and dry cleaning by commercial materials. The results showed that the $\mathrm{CO}_{2}$ snow jet is able to effectively remove particles from the paper surface and did not cause any observable degradation. The $\mathrm{CO}_{2}$ snow jet cleaning compared with the mechanical dry cleaning showed similar effectiveness without any adverse effects on the paper surface. It was proved that the $\mathrm{CO}_{2}$ snow technique is a suitable method for cleaning common types of paper materials.
\end{abstract}

Keywords: $\mathrm{CO}_{2}$ snow jet, Dry ice, Dry cleaning, Co-axial nozzle, Paper

\section{Introduction}

Particles suspended in the indoor air cause adverse effects on library and archival collections. Generated by various indoor and outdoor sources, they represent a complex mixture of particles that differ widely in chemical composition and size. Typical indoor sources in libraries and archives are related to activities conducted indoors (such as maintenance or cleaning) and in rooms accessible to public and visitors (skin and clothing abrasion, mineral particles brought on shoes) [1-5]. These processes are the principal sources of coarse particles ( $1 \mu \mathrm{m}$ ) composed mainly of organic and mineral matter. The major source of indoor fine particles $(<1 \mu \mathrm{m})$ is the ambient accumulation mode particles $(0.1-1 \mu \mathrm{m})$, unfiltered indoors through the building envelope $[6,7]$. These particles represent the most harmful portion: they consist of elemental carbon (soot) directly emitted from combustion and organic matter, and ammonium sulphate and nitrate formed by gas-to-particle conversion $[6,8-10]$. Due to the small size, they infiltrate from ambient air most easily and once indoors they deposit onto

\footnotetext{
*Correspondence: maskova@icpf.cas.cz

${ }^{1}$ Institute of Chemical Process Fundamentals, The Czech Academy

of Sciences, Rozvojová 135, 16502 Prague 6, Czech Republic

Full list of author information is available at the end of the article
}

all available surfaces, penetrating into books and porous surfaces $[11,12]$. Organic matter and ammonium sulphate contribute to chemical degradation of paper, and fine carbonaceous particles cause the soiling of surfaces and absorbtion of gaseous pollutants [13-15].

To minimise the adverse effects, books and documents should be kept free of dust. The simple technique for removing surface deposits is dry cleaning, which is done using brushes, erasers, and sponges. For documents in good condition, the surface can be lightly dusted with a soft brush in combination with a vacuum cleaner. More stubborn dirt can be removed with a plastic eraser. Surface cleaning sponges can be used for sooty or mouldy deposits [16]. Prior to the cleaning, it should be taken into account that the cleaning treatment can also affect the physical state of documents. Some erasers cause abrasion and leave a detectable amount of eraser material within the fibres of paper and textiles, altering surface colour, brightness and texture. The wrong cleaning technique can also ingrain fine particles deeper into porous paper or fibres of textiles [17-20].

Alternative dry cleaning techniques include surface cleaning using a high-speed air jet, carbon dioxide $\left(\mathrm{CO}_{2}\right)$ snow or carbon dioxide (dry ice) pellet blasting. Particle detachment is caused by drag force from the highspeed gas flow, enhanced by collision force of fine dry ice

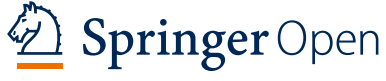

(c) The Author(s) 2021. Open Access This article is licensed under a Creative Commons Attribution 4.0 International License, which permits use, sharing, adaptation, distribution and reproduction in any medium or format, as long as you give appropriate credit to the original author(s) and the source, provide a link to the Creative Commons licence, and indicate if changes were made. The images or other third party material in this article are included in the article's Creative Commons licence, unless indicated otherwise in a credit line to the material. If material is not included in the article's Creative Commons licence and your intended use is not permitted by statutory regulation or exceeds the permitted use, you will need to obtain permission directly from the copyright holder. To view a copy of this licence, visit http://creativecommons.org/licenses/by/4.0/. The Creative Commons Public Domain Dedication waiver (http://creativeco mmons.org/publicdomain/zero/1.0/) applies to the data made available in this article, unless otherwise stated in a credit line to the data. 
particles formed in jet by expansion of liquid $\mathrm{CO}_{2}$ or large $\mathrm{CO}_{2}$ particles mixed into the air flow. Most all of these techniques primarily developed for specific needs of the aerospace and micro-electronics industries are now used in many other applications [21]. Dry ice snow and dry ice blasting have previously been tested in cleaning of some historical artefacts and art objects, particularly to evaluate certain positive characteristics such as the fast and non-aggressive cleaning of some materials, and the ease of waste removal.

Sherman et al. [22] performed tests of $\mathrm{CO}_{2}$ snow for the removal of particle and hydrocarbon-based contaminants from the surface of different materials (metals, semiconductors, ceramics, glass, polymers) with particular note given to reduction of surface hydrocarbons. The $\mathrm{CO}_{2}$ snow cleaning measurements were compared with samples which were cleaned using a conventional solvent process. The results showed that the $\mathrm{CO}_{2}$ snow cleaning is comparable to the solvent cleaning. It was also observed that $\mathrm{CO}_{2}$ snow removed particles and other debris and therefore it was recommended for other applications.

Shockey [23], in an early application of $\mathrm{CO}_{2}$ snow on art objects, removed a white haze formed by crystalline deposits on Robert Morris's Model structure made of cellulose acetate butyrate at the Smithsonian. Odegaard [24] used carbon dioxide snow, generated by the liquid $\mathrm{CO}_{2}$ technique to clean textiles and basketry. In tests, the samples of basketry and basketry/textiles dusted with artificial dust were cleaned either by brushing, brushing/ vacuum cleaning or $\mathrm{CO}_{2}$ snow. The cleaning efficiency determined by weight was approximately $71-79 \%$ for liquid $\mathrm{CO}_{2}$ and between 44 and $54 \%$ for both brushing methods.

Tsang and Babo [25] performed tests of fine soot particle removal, partially embedded in surface of acrylic emulsion paint. In tests the $\mathrm{CO}_{2}$ snow method was compared with atomic oxygen cleaning and the traditional dry cleaning with different commercial dry cleaning products recommended for smoke-damaged artworks. $\mathrm{CO}_{2}$ cleaning did not effectively remove soot most probably due to presence of embedded fine particles and caused small impact holes, indicating loss of original matter.

Součková et al. [26] compared $\mathrm{CO}_{2}$ snow and nitrogen jet cleaning with infrared TEA $\mathrm{CO}_{2}$ laser cleaning of vegetable tanned calf leather. The results showed that the perceptible damage was observed by the SEM after the nitrogen jet cleaning and increased after the $\mathrm{CO}_{2}$ snow application. However, the laser cleaning (fluency $0.69 \mathrm{~J} / \mathrm{cm}^{2}$, pulse duration $100 \mathrm{~ns}$, number of pulses 2-500) removed particles already after irradiation by 2 pulses with the efficiency increasing with the number of pulses but with perceptible degradation that occurred after irradiation of 50 pulses. Dry ice blasting and wiping-and-vacuuming have been used to remove soot from books exposed to smoke [20, 27]. Molen et al. [28] and Cutulle and Kim [29] measured the performance and efficiency of dry ice blasting in the removal of coatings from metallic artifacts. The results showed that all techniques are faster than the classical dry cleaning. Dry ice blasting was the most effective in the cleaning of metallic artifacts $[28,29]$, quite effective in removing soot from canvas, and leather bookbindings [20, 27]. Also, in the above study $\mathrm{CO}_{2}$ snow cleaning of polymer surfaces was less effective and even caused some damage to surfaces [25]. One study documented damage while cleaning vegetable tanned calf leather [26].

As discovered, these methods proved to be viable but have also some limitations, related to the rapid decrease of the local temperature and the mechanical strength of the jet which can contribute to the surface damage of the more sensitive materials [25]. To minimize the potential damage, the less aggressive cleaning conditions with lower but still acceptable efficiency of particle removal could be used [30]. Therefore, to avoid possible physical damage, tests are needed prior to the application of any of these methods.

In this study, we performed tests of nitrogen highspeed jet and $\mathrm{CO}_{2}$ snow cleaning of rough (cottonbased) and smooth (wood-based) paper surface, soiled by submicron particles, typical for the naturally ventilated depositories. Cotton paper has been used since the fifteenth century but was replaced by wood pulp paper in the nineteenth century. As a result, cotton cellulose is a typical raw material found in collections of early printed books and wood cellulose is common for modern printed books. Cotton cellulose differs from wood cellulose by having higher degrees of polymerization and crystallinity, which makes cotton paper more stable and resistant to the physical and chemical changes [31].

We also performed tests of the cleaning of paper soiled by typical dust collected in a library and two synthetic dusts composed mainly by mineral dust and/or carbonaceous particles. We then compared the results with traditional dry-cleaning of the same samples. The experimental results were compared with the theoretical calculations of removal and adhesion forces. The purpose was to discover the suitability and conditions for high-speed jet and $\mathrm{CO}_{2}$ snow cleaning as an alternative method for removal of fine dust particles from the surfaces of books and manuscripts. 


\section{Methodology}

\section{$\mathrm{CO}_{2}$ snow jet}

Tests of $\mathrm{CO}_{2}$ snow cleaning were performed using a Precision Spray Cleaning Pen (SnoPen SP 2000, Cleanlogix) [32]. This instrument generates a $\mathrm{CO}_{2}$ snow spray cleaning stream of dry ice snow particles supported by a co-axial nitrogen flow at high-velocity. The particles are formed by a flash-atomization of liquid carbon dioxide delivered to the inner nozzle from the pressure cylinder and accelerated by the high-velocity flow of nitrogen from the outer nozzle. The flow rate of nitrogen is controlled independently by injection pressure (0.08$0.50 \mathrm{MPa}$ ). The liquid carbon dioxide supply is controlled by a micro metering valve and operates only with the co-axial flow of nitrogen. As stated by the producer, the flow rates of both components are the main factors determining the spray characteristics and by combination of both parameters one can arrange proper cleaning conditions-efficient cleaning and no physical damage of the cleaned object.

The properties of the $\mathrm{CO}_{2}$ snow jet were characterised. The volume flow rate of nitrogen was measured using a glass rotameter (accuracy of $4 \%$ ). To determine the mass flow rate of the carbon dioxide, the stream of gases and dry ice particles passed first through a heat exchanger where all particles of $\mathrm{CO}_{2}$ evaporated. The volumetric flow rate of remaining gaseous mixture was again measured by the rotameter and the flow rate of $\mathrm{CO}_{2}$ was calculated subtracting the previously measured $\mathrm{N}_{2}$ flow rate. Every measurement was repeated three times.

The shape of the jet was simultaneously determined using the flow field visualisation by the particle image velocimetry (PIV, Dantec Dynamics, laser Quantronix
Darwin Duo $80 \mathrm{~W}$, high-speed camera Photron Fastcam Mini SX200). In addition, the local impaction pressure was measured by a pressure sensor AP-43 (Keyence corp.) and the temperature of the surface by an infrared thermal-imaging camera (Testo 872) at the impaction point of the jet. Every measurement was repeated three times.

\section{Paper samples \\ Samples preparation}

Two types of paper (cotton-based and wood-based) were used for tests. The results were subsequently verified using historical paper. The sheets of different types of paper were cut with scissors into $30 \times 30 \mathrm{~mm}$ samples.

The tests were performed with two samples of paper: Whatman Grade 1 filter paper and Holmen BOOK Cream 2.0 paper. The papers differ in quality innate to the raw materials and manufacturing process. Whatman filter paper is composed of cotton cellulose fibres which cling together forming a porous structure. Holmen paper is made from fresh wood fibres. It is made up of $81-86 \%$ mechanical pulp and 7-12\% pigments and fillers (chalk and clay). The paper has a smooth surface suitable for printing. The surface structure of both papers is shown in Fig. 1.

The methods were then verified utilizing a sheet of paper stored for approx. 60 years in a depository of the National Archives in Prague (Fig. 2). The type of paper was identified using the phloroglucinol solution by a drop method.

The Whatman paper samples were soiled with various fine particles representing dirt: soot generated by a candle, PM1 ambient particles, and laboratory-generated
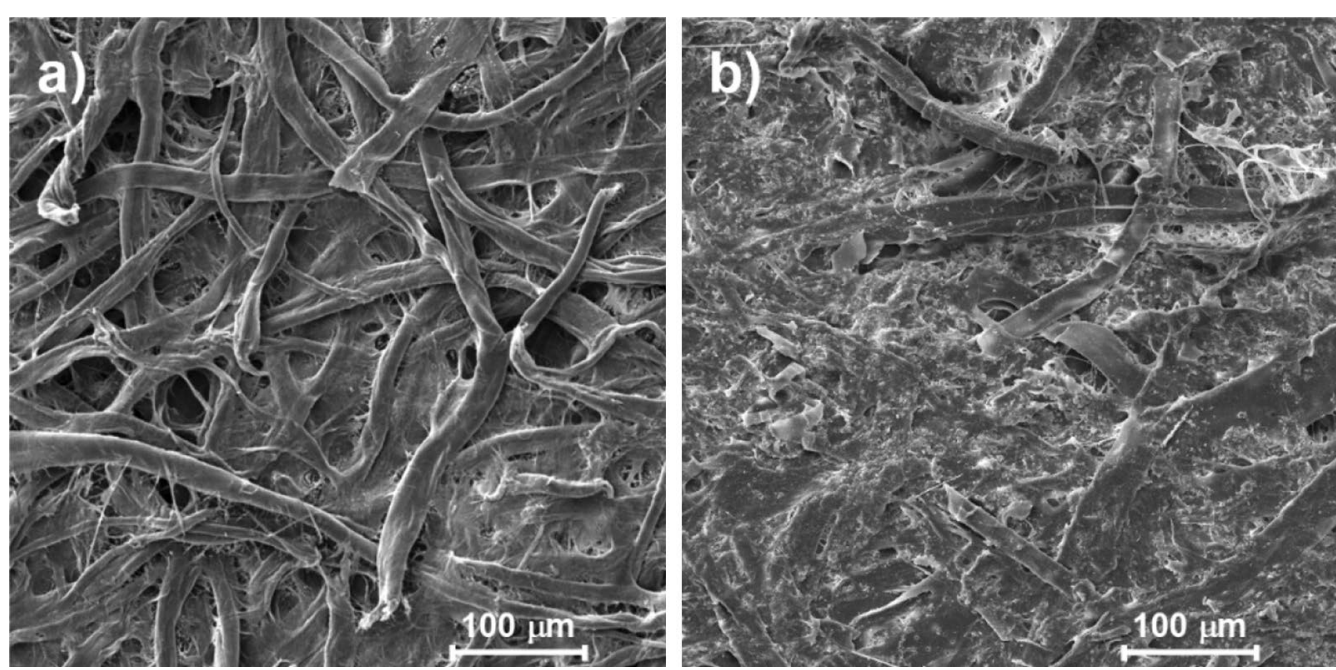

Fig. 1 Scanning electron micrographs of a Whatman paper and $\mathbf{b}$ Holmen paper 


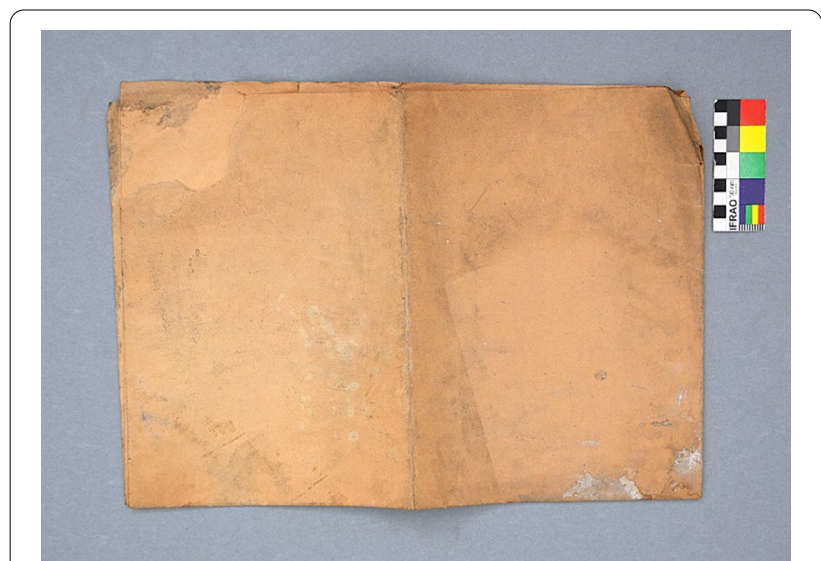

Fig. 2 The sheet of archival paper used for tests

monodisperse ammonium sulphate. Soot and PM1 particles were collected using a Leckel LVS-3 sampler (Sven Leckel Ingenieurbüro). Monodisperse ammonium sulphate particles were deposited using equipment described in a previous study [33].

In addition, Whatman and Holmen paper samples were soiled with typical dust collected in depositories of the National Library of the Czech Republic during the cleaning of books with the Depulvera book cleaning machine, as well as with two commercial synthetic dusts: Ashrae 52.1 (Powder Technology Ltd. UK) and Ivory Black 12,000 (Kremer Pigmente GmbH \& Co., Germany). The Library Dust is composed mainly of organic matter [6], Ashrae Dust consists of $72 \%$ mineral matter, $23 \%$ carbon black soot and $5 \%$ cotton fibres [34]. The Ivory Black is a black pigment composed of charred ivory and calcium phosphate [35]. The samples were contaminated by the dust using a brush and evenly distributed on the surfaces by a rubber roller. A list of samples is provided in Table 1.

Table 1 List of samples

\begin{tabular}{lllll}
\hline Soiling & Type & Paper & & \\
\cline { 3 - 5 } & & Whatman & Holmen & Archival \\
\hline None & - & $X$ & $X$ & \\
Artificial & PM1 & $X$ & & \\
& Ammonium sulphate & $X$ & & \\
& Soot & $X$ & & \\
& Library Dust & $X$ & $X$ & \\
& Ashrae Dust & $X$ & $X$ & \\
& Ivory Black & $X$ & $X$ & \\
Natural & - & & & $X$ \\
\hline
\end{tabular}

\section{Cleaning}

The cleaning by the nitrogen and $\mathrm{CO}_{2}$ snow jets was performed with the angle between the nozzle and the surface of $45^{\circ}$ or less and the distance between the nozzle tip and the surface approximately $30 \mathrm{~mm}$. The nozzle was moved from side to side in 4 passages from the bottom of the sample to the top with speed approximately $1-10 \mathrm{~cm} / \mathrm{s}$. Co-axial flow of $99.99 \%$ nitrogen was used for prevention of moisture condensation. The sample was fixed on a raised metal screen (Fig. 3).

For comparison, tests of several commercial materials used for traditional dry cleaning were also performed. As a suitable for cleaning, two sponges (Wallmaster and the white soft side of Wishab), the white soft side of a FaberCastell eraser 7082-20 and the kneadable eraser Groom/ Stick were used. For cleaning, back-and-forth motionsvertical followed by horizontal-were performed.

\section{Analysis}

The effects of the treatments were examined microscopically and analysed by the colour, the folding endurance, and the $\mathrm{pH}$ of the cold water extract of the paper measured before and after the treatment.

Microscopic analyses were performed using a scanning electron microscope (SEM, Tescan Indusem, samples coated by $\mathrm{Au}$ ) and a 3D optical microscope (Hirox RH 2000).

Colour change was measured by a photospectrometer (CM-700d, Konica Minolta) four times before and after cleaning each sample and evaluated using the CIE lab colour space, where $L^{*}, a^{*}$, and $b^{*}$ represent black-white,

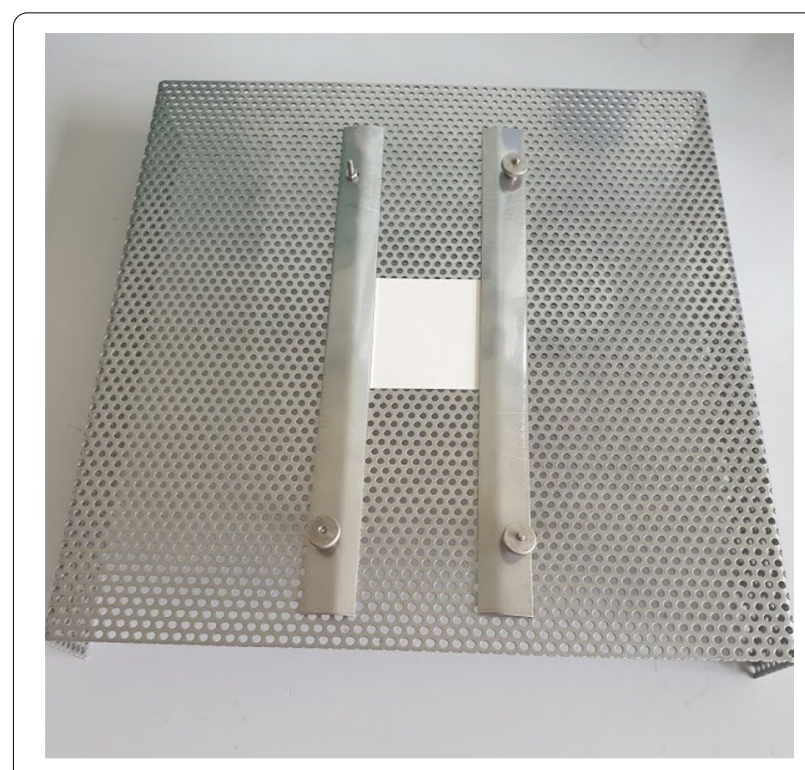

Fig. 3 A sample fixed on the raised metal screen 
red-green, and yellow-blue scales, respectively. The colour measurements were performed before and after the treatments and the average differences $\left(\Delta L^{*}, \Delta a^{*}\right.$, and $\left.\Delta b^{*}\right)$ were used to calculate the total colour change $(\Delta E)$ :

$$
\Delta E=\sqrt{\left(\Delta L^{*}\right)^{2}+\left(\Delta a^{*}\right)^{2}+\left(\Delta b^{*}\right)^{2}}
$$

Because the CIELab space is nonuniform the results were compared with the formula $\triangle E 2000$ (mathematically expanded) calculated according to Luo et al. [36]. This formula is used especially for determining the colour difference in its assessment of industrial products.

In case of samples artificially soiled by Library Dust, Ashrae Dust, and Ivory Black, only the dominant parameter $L^{*}$ was used to evaluate the effectiveness $(\eta)(\%)$ :

$$
\eta \approx \frac{\Delta L_{p}-\Delta L_{c}}{\Delta L_{p}} \bullet 100
$$

where $\Delta L_{p}$ are values of $L^{*}$ measured before after the dust application and $\Delta L_{c}$ are values of $L^{*}$ measured before and after the cleaning.

Folding endurance was measured by a twin folder tester $(13,505$, Schopper-Frank) under a standard tension of $9.81 \mathrm{~N}$ as a number of double folds for the machine and cross directions using 10 parallel samples for each direction. Before measuring, the samples were conditioned at a temperature of $23.0{ }^{\circ} \mathrm{C}$ and relative humidity $50.0 \%$ [37]. Further, the $\mathrm{pH}$ value of the cold-water extracts was measured using a pH Meter Orion Star A214 with an Orion 8172BNWP ROSS Sure-Flow pH electrode (Thermo Scientific) using 10 parallel samples.

The efficiency of removal of PM1 and the ammonium sulphate particles was evaluated using sulphate concentration analysed before and after the cleaning by Ion Chromatography (Dionex ICS-5000, Thermo Scientific). The soot samples were analysed gravimetrically by weighing filters before and after exposition, and before and after cleaning using microbalance with $\pm 1 \mu \mathrm{g}$ sensitivity (Sartorius M5P, Data Weighing Systems). The analytical procedure is described in detail in the previous study [6]. The measurements were performed using two parallel samples. The cleaning efficiency $\phi(-)$ was approximated by:

$$
\varphi=1-\frac{C_{a}}{C_{b}}
$$

where $C_{a}$ and $C_{b}\left(\mu \mathrm{g} / \mathrm{cm}^{2}\right)$ are the mass concentrations of soot and/or sulphate after and before cleaning.

Further, a potential long-term effect of cleaning was tested using accelerated thermal aging at $105^{\circ} \mathrm{C}$ for $144 \mathrm{~h}$ [38]. The tests were performed for clean and Ivory Black samples of the Holmen paper.

\section{Modelling}

The model compared drag and collision forces exerted on adhered particles by the nitrogen jet and the $\mathrm{CO}_{2}$ snow jet and the van der Waals adhesive force binding the contaminant to the surface. The forces were calculated at conditions the experiments were performed assuming the contaminant removal can occur when removal forces overcome the adhesive force (see Additional file 1).

\section{Results}

\section{Characterization of the jet}

The effect of flow rates of both components on characteristic features of the $\mathrm{CO}_{2}$ snow jet (velocity, shape, pressure, temperature) was examined. The co-axial nozzle comprises an inner circular tube with diameter $0.8 \mathrm{~mm}$ and an outer annular tube with inner and outer diameter $1.5 \mathrm{~mm}$ and $2.0 \mathrm{~mm}$, respectively (Fig. 4).

The results showed that the volume flow rate of nitrogen ranged from 0.3 to $1.4 \mathrm{l} / \mathrm{s}$ and increased linearly with the injection pressure $(0.08-0.50 \mathrm{MPa})$. Further, the mass flow of liquid carbon dioxide ranged approximately from 2.5 to $4.0 \mathrm{~g} / \mathrm{s}$ (minimal and maximal adjustable feeding). The $\mathrm{CO}_{2}$ snow jet was partially focused with increasing nitrogen flow producing narrower cone spray (Fig. 5a, b), whereas the influence of the $\mathrm{CO}_{2}$ flow rate was negligible (Fig. 5c, d).

The results also revealed that the local impaction pressure increased with both the volume flow rate of the coaxial nitrogen and the mass flow rate of carbon dioxide (Fig. 6) and that the $\mathrm{CO}_{2}$ snow jet caused a rapid decrease of the surface temperature $\left(10-20{ }^{\circ} \mathrm{C} / \mathrm{s}\right)$ of the cleaned material.

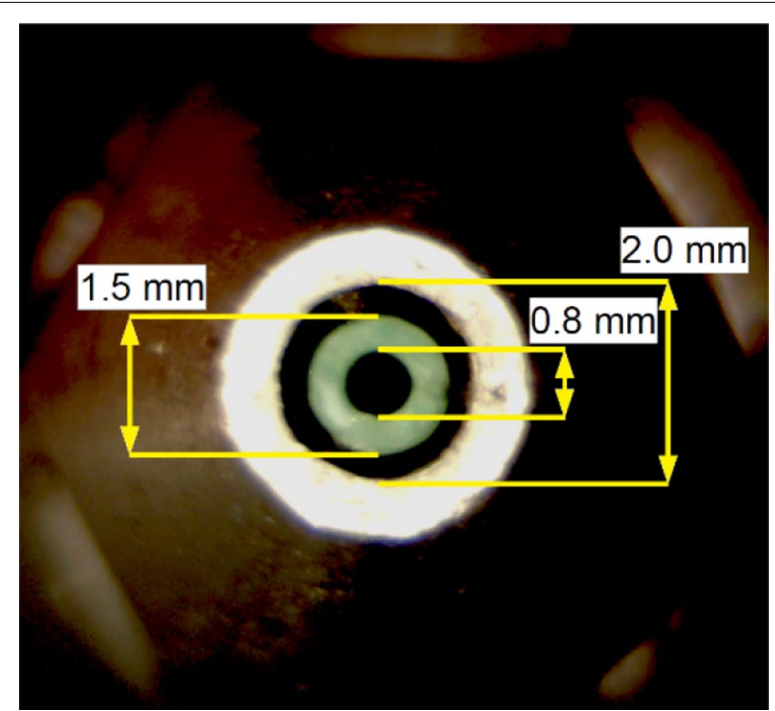

Fig. 4 The co-axial nozzle 


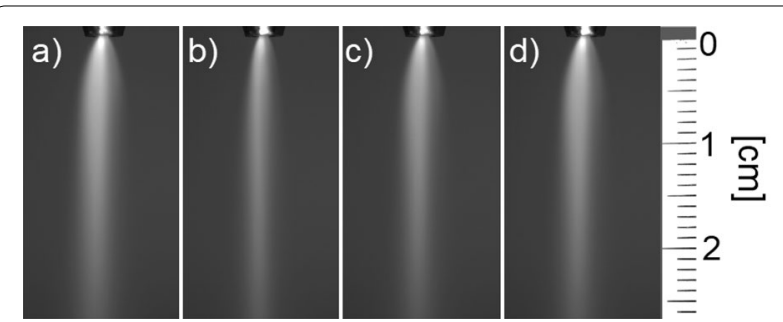

Fig. 5 The spray cone shape with a the $\mathrm{CO}_{2}$ flow rate $3.3 \mathrm{~g} / \mathrm{s}$ and the $\mathrm{N}_{2}$ flow rate $0.3 \mathrm{l} / \mathrm{s}, \mathbf{b}$ the $\mathrm{CO}_{2}$ flow rate $3.3 \mathrm{~g} / \mathrm{s}$ and the $\mathrm{N}_{2}$ flow rate $1.4 \mathrm{l} / \mathrm{s}, \mathbf{c}$ the $\mathrm{CO}_{2}$ flow rate $2.5 \mathrm{~g} / \mathrm{s}$ and the $\mathrm{N}_{2}$ flow rate $0.6 \mathrm{l} / \mathrm{s}$, and $\mathbf{d}$ the $\mathrm{CO}_{2}$ flow rate $4.0 \mathrm{~g} / \mathrm{s}$ and the $\mathrm{N}_{2}$ flow rate $0.6 \mathrm{l} / \mathrm{s}$

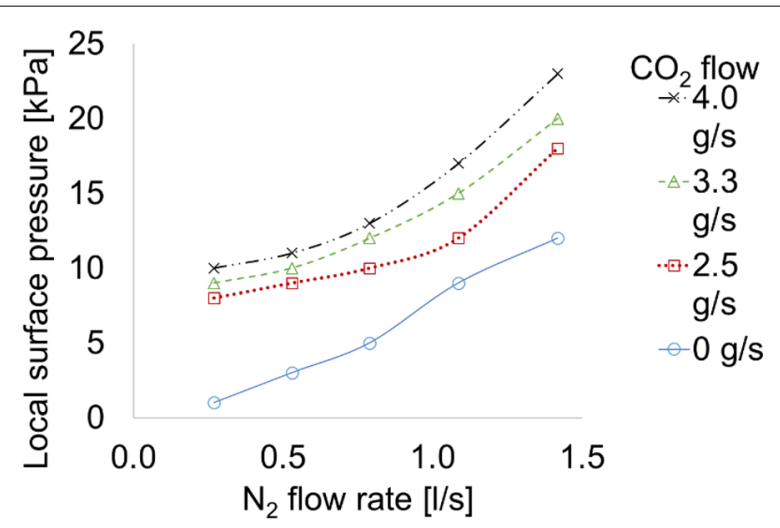

Fig. 6 Influence of flow rates of nitrogen and carbon dioxide on the local surface pressure (angle between nozzle and the surface $45^{\circ}$ and the distance between the nozzle tip and the surface $30 \mathrm{~mm}$ )

Table 2 Change of the minimal surface temperature of paper before and after the treatement by the $\mathrm{CO}_{2}$ snow jet with the carbon dioxide flow rate $3.0 \mathrm{~g} / \mathrm{s}$ and different nitrogen flow rates

\begin{tabular}{lll}
\hline $\mathbf{N}_{\mathbf{2}}$ flow rate $(\mathbf{I} / \mathbf{s})$ & Whatman $\left({ }^{\circ} \mathbf{C}\right)$ & Holmen $\left({ }^{\circ} \mathbf{C}\right)$ \\
\hline 0.3 & $-30.6 \pm(1.9)$ & $-31.0 \pm(1.5)$ \\
0.6 & $-32.0 \pm(1.8)$ & $-32.9 \pm(1.1)$ \\
1.4 & $-34.6 \pm(2.3)$ & $-36.7 \pm(2.2)$ \\
\hline
\end{tabular}

In an additional test, we attempted to discover whether a higher co-axial flow of nitrogen with ambient temperature of approximately $20{ }^{\circ} \mathrm{C}$ could compensate the cooling effect of the jet. However, we found that while increasing the flow rate of nitrogen, the cooling rate of the jet could slightly increase as well (Table 2; Fig. 7). The results also showed that after treatment using only the nitrogen jet, the surface temperature change was negligible.

The explanation may be that due to the higher flow rate, fewer of the dry ice particles evaporate in the jet but more upon impaction surface, enhancing the cooling effect [39].

\section{Cleaning of paper}

Two criteria were considered when assessing suitability: (a) the method should not cause any damage and (b) it should be sufficiently effective.

\section{Degradation}

The first tests were performed to determine the effect of the cleaning conditions on the properties of the less stable Holmen paper. The purpose was to assess any possible surface damage caused by the incident jets. The first set of parallel samples was cleaned by the $\mathrm{CO}_{2}$ snow jet with a carbon dioxide flow rate of $3.0 \mathrm{~g} / \mathrm{s}$ and a nitrogen flow rate of $1.4 \mathrm{l} / \mathrm{s}$. The second set was treated using only the nitrogen jet at the same flow rate.

The effects of the treatment were examined microscopically and analysed according to the colour change, the folding endurance, and the $\mathrm{pH}$ value of the coldwater extract of the paper as measured before and after the treatment. The colour measurements reflect changes of the esthetical value, the folding endurance is sensitive to changes in the structural properties of paper and $\mathrm{pH}$ indicates any changes of stability. All of these methods are commonly used for the evaluation of paper conservation interventions $[40,41]$ and their combination can provide more comprehensive information about paper properties.

The microscopic observation did not show any remarkable changes in the surface structure nor any significant changes of the fibres' surface. With respect to the minimal change in colour perceptible by humans, defined as $\Delta E=1.00$ [42], both jets did not cause any visually perceived change of the surface (Table 3 ). A change in yellowness $\leq 0.5$ points after treatment specified as a high optical stability of paper [43] might also indicate negligible effect on optical properties.

The results of the folding endurance tests did not show any effect caused by the nitrogen jet in machine direction folding strength. The $\mathrm{CO}_{2}$ snow jet caused a decrease of about $20 \%$ in the machine direction folding strength. Both jets also caused a decrease of about $20 \%$ in the cross direction folding strength (Table 4). With respect to known high scatter in measurements of the folding endurance [31] and a loss of fold endurance $\leq 50 \%$ after accelerated aging specified as high strength stability of printing and writing paper [44], the jet cleaning caused insignificant changes of structure.

The tests of $\mathrm{pH}$ value of the cold-water extracts revealed that the average $\mathrm{pH}$ value of 7.8 measured before the treatment remained practically unchanged, with only a small increase of approximately $1.4 \%$ after 


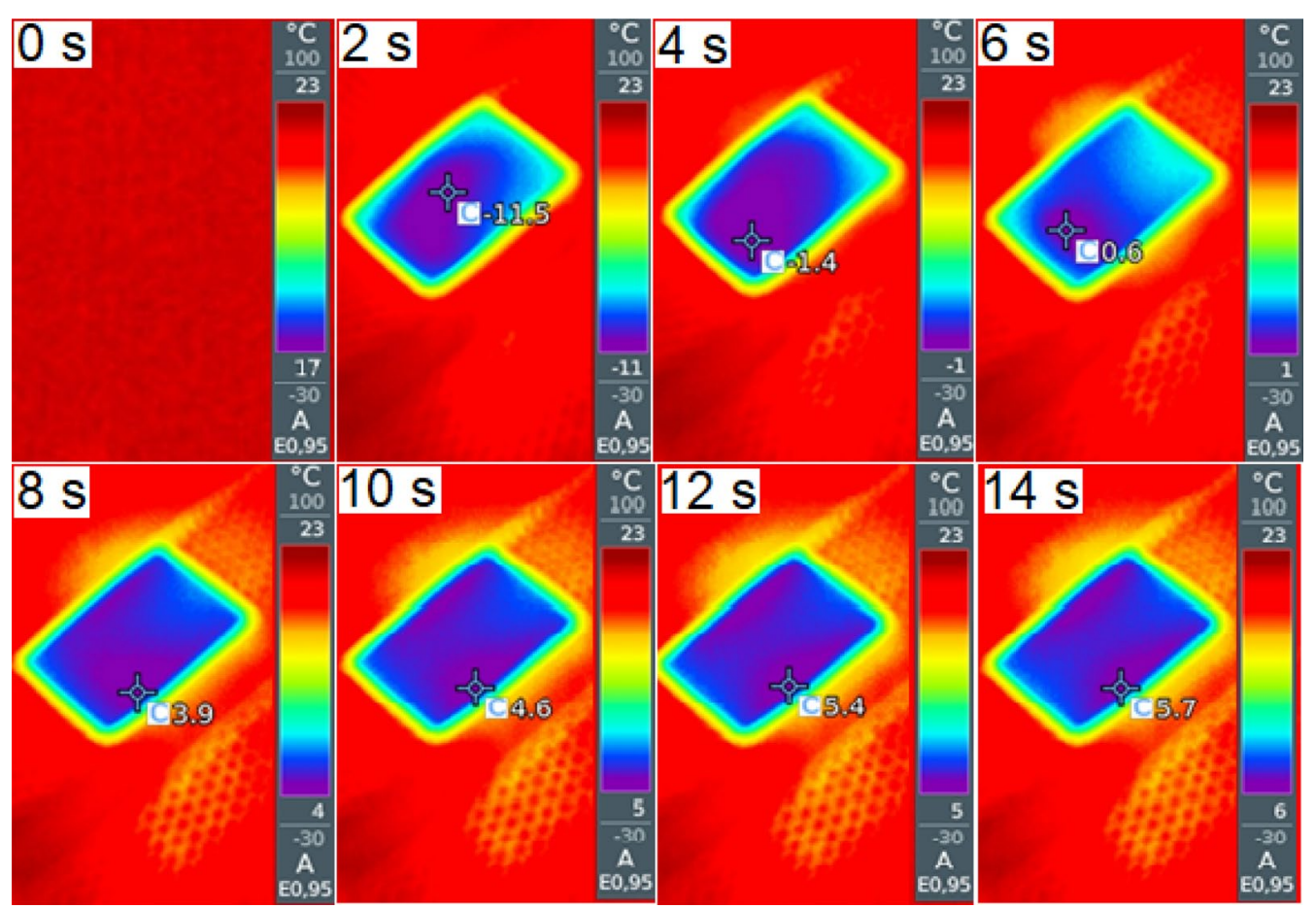

Fig. 7 Example of time behaviour of the surface temperature of a Holmen paper sample fixed on the desk (carbon dioxide flow rate $3.0 \mathrm{~g} / \mathrm{s}$, nitrogen flow rate $0.6 \mathrm{l} / \mathrm{s}$ ) — colormaps with detection of the minimal temperature spot $(\mathrm{t}=0 \mathrm{~s}$-before the treatement, $\mathrm{t}=2 \mathrm{~s}$-end of the treatment)

Table 3 Colour change of the Holmen paper caused by the nitrogen jet and the $\mathrm{CO}_{2}$ snow jet ( \pm SD)

\begin{tabular}{llllll}
\hline & $\boldsymbol{\Delta} \boldsymbol{L}^{*}$ & $\boldsymbol{\Delta \boldsymbol { a } ^ { * }}$ & $\boldsymbol{\Delta} \boldsymbol{b}^{\boldsymbol{*}}$ & $\boldsymbol{\Delta E}$ & $\boldsymbol{\Delta E 2 0 0 0}$ \\
\hline $\mathrm{N}_{2}$ jet & $-0.10( \pm 0.37)$ & $0.00( \pm 0.15)$ & $0.11( \pm 0.28)$ & $0.50( \pm 0.15)$ & $0.35( \pm 0.15)$ \\
$\mathrm{CO}_{2}$ snow jet & $-0.34( \pm 0.23)$ & $0.12( \pm 0.08)$ & $0.19( \pm 0.21)$ & $0.43( \pm 0.18)$ & $0.37( \pm 0.12)$ \\
\hline
\end{tabular}

Table 4 Folding endurance of the Holmen paper treated by the nitrogen jet and the $\mathrm{CO}_{2}$ snow jet

\begin{tabular}{llll}
\hline & No treatment & $\mathbf{N}_{\mathbf{2}}$ jet & $\mathrm{CO}_{\mathbf{2}}$ snow jet \\
\hline Machine direction & $54.9( \pm 14.0)$ & $54.8( \pm 13.5)$ & $45.7( \pm 9.7)$ \\
Cross direction & $4.2( \pm 0.4)$ & $3.3( \pm 0.7)$ & $3.4( \pm 0.8)$ \\
\hline
\end{tabular}

the application of the nitrogen jet and of approximately $2.8 \%$ after the $\mathrm{CO}_{2}$ snow jet treatment.

As found, both jet cleaning techniques did not cause any significant alteration of the examined properties and/or any observable changes of surface structure. With respect to the low resistant form of cellulose used in the test, the snow jet can be safely used for cleaning of surfaces of common types of pure cellulose paper.

\section{Effectiveness}

The efficiency of the fine particles removal was examined using three types of particles deposited on the Whatman paper (PM1, ammonium sulphate, and soot). The average mode size of the PM1 fraction reported by Mašková et al. [7] was $0.3 \mu \mathrm{m}$ with the geometric standard deviation (GSD) of 1.83. Laboratory generated ammonium sulphate and soot had modes of the mass concentration at 0.2 and $0.12 \mu \mathrm{m}$ with the GSD of 1.29 and 1.68 , respectively. The samples were cleaned by the nitrogen jet and by the $\mathrm{CO}_{2}$ snow jet with nitrogen flow rates of $0.3,0.6$, and $1.41 / \mathrm{s}$ and the constant flow rate of carbon dioxide of $3.0 \mathrm{~g} / \mathrm{s}$.

Figure 8 shows the cleaning efficiency as a parameter of the nitrogen flow rate. The nitrogen jet alone was almost inefficient in the removal of the submicronsized particles. When adding the dry ice cleaning, submicron-sized particles were removed with a removal 


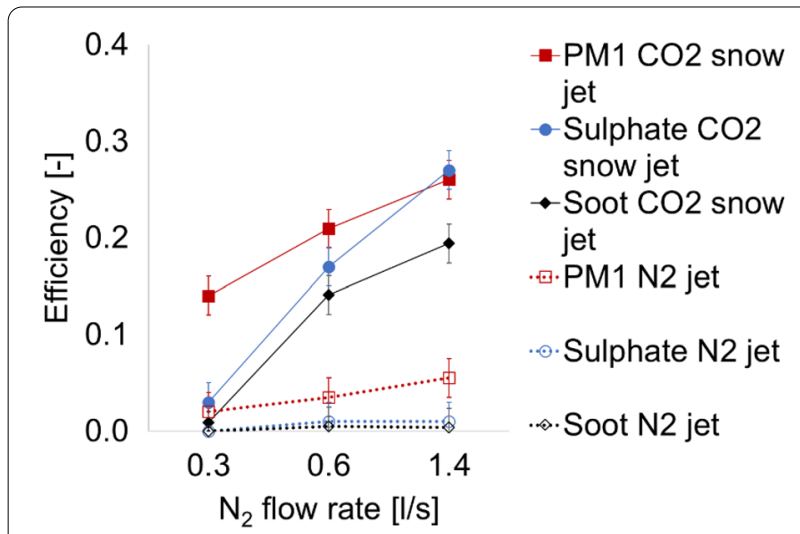

Fig. 8 Effect of the $\mathrm{N}_{2}$ flow rate on the cleaning efficiency of submicron particles by the nitrogen jet and the $\mathrm{CO}_{2}$ snow jet

efficiency quickly rising with an increase in the nitrogen flow rate.

The surface of samples was also examined by the SEM microscope. The results showed that the $\mathrm{CO}_{2}$ snow jet can also remove particles ingrained into the surface. An example of soot particle removal using the nitrogen jet and the $\mathrm{CO}_{2}$ snow jet is shown in Fig. 9 .

\section{Comparison of the jet and mechanical dry cleaning methods}

The last phase tests were conducted to compare the effectiveness of the both jet-cleaning methods with the classical dry-cleaning performed with commercial materials. The experiments used samples of the Whatman and Holmen papers, contaminated by dust collected in library depositories and two commercial synthetic dusts Ashrae Dust and Ivory Black.

As found from the observations samples with the Library Dust were cleaned most easily, cleaning of samples with the Ivory Black was more difficult, and the Ashrae Dust was the most resistant. The cleaning of the Holmen paper was overall more efficient than the cleaning of the Whatman paper. The results also revealed that both techniques did not cause any alteration of the surface. The examples of the $\mathrm{CO}_{2}$ snow cleaning of the Whatman paper contaminated by the Ashrae Dust and by the Ivory Black are shown in Fig. 10.

The results were evaluated by visual observation, optical and SEM microscopes, and by measuring the colour change. The colour measurement showed that the most efficient was the Groom/Stick eraser, followed by the Faber Castell, and less efficient were the Wallmaster and Wishab sponges. Further, the Library Dust was removed most easily, the cleaning of samples with the Ivory Black was more difficult with a tendency to smear and the Ashrae Dust was the most resistant. The SEM examination showed that all materials caused some damage to the Holmen paper with visible crumbs of the Wishab eraser remaining (Fig. 11b), released fibres (Fig. 11a, c, d) and even changes of fibres surface after the Faber Castell application (Fig. 11d). In contrast, neither jet caused any alteration of the Holmen paper surface (Fig. 11e, f). It was also found that the mechanical cleaning could not remove contaminant particles embedded in the the paper's surface and even led to the ingraining of some powder into the fibrous structure.
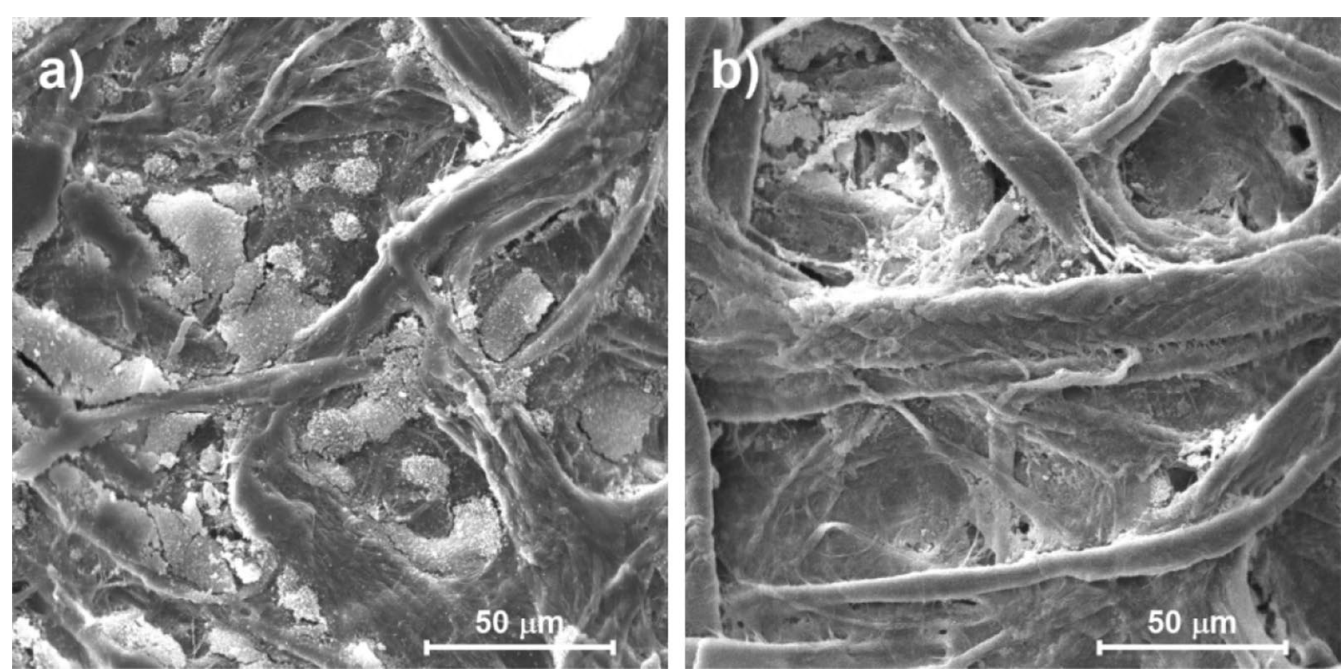

Fig. 9 Example of soot particle removal from the Whatman paper using a the nitrogen jet and $\mathbf{b}$ the $\mathrm{CO}_{2}$ snow jet (see the clean Whatman paper in Fig. 1) 


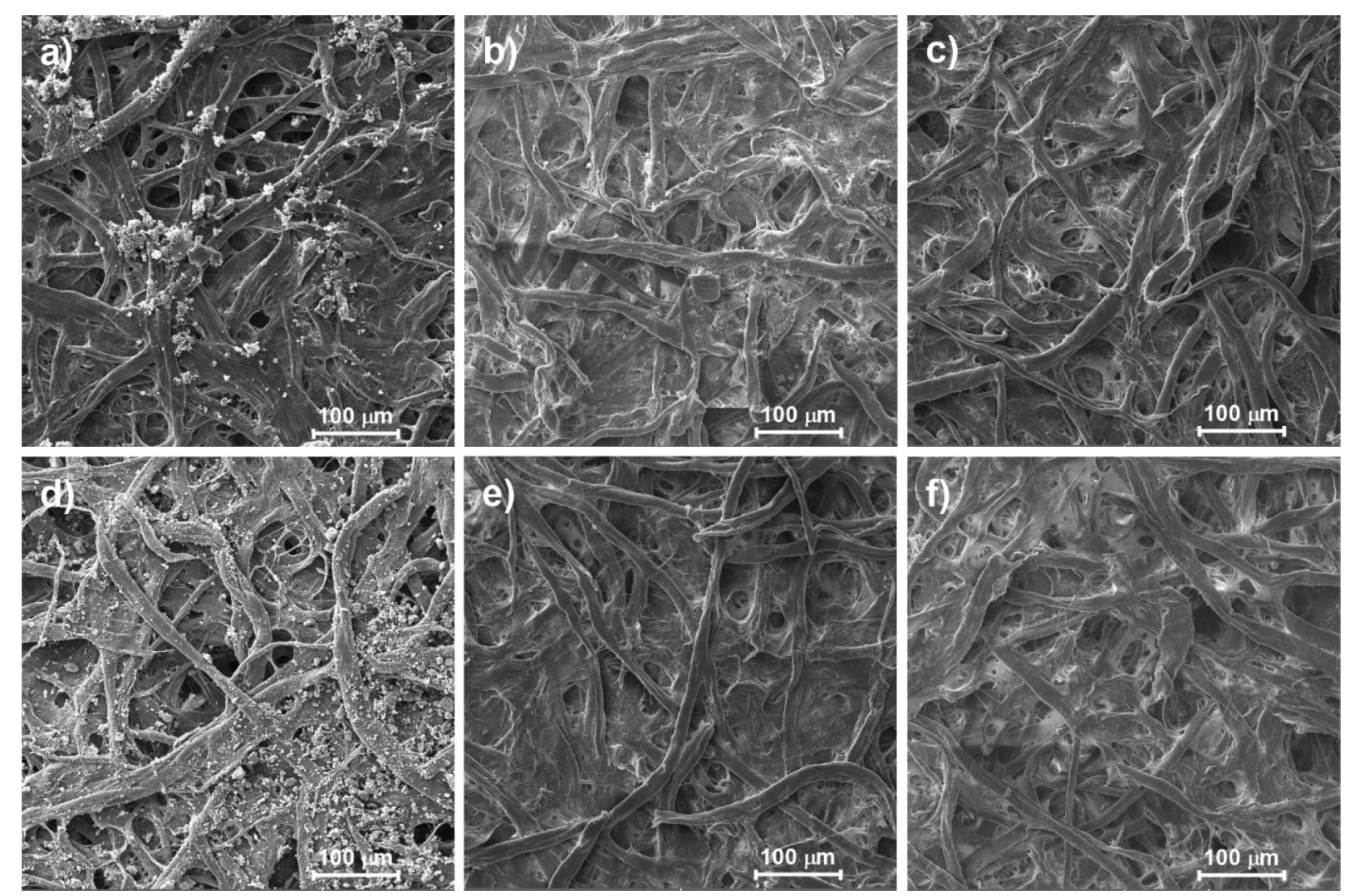

Fig. 10 Example of Whatman filters contaminated by the Ashrae Dust $\mathbf{a}$ before cleaning, $\mathbf{b}$ after leaning by the nitrogen jet, and $\mathbf{c}$ after cleaning by the $\mathrm{CO}_{2}$ snow jet and by the Ivory Black $\mathbf{d}$ before cleaning, e after cleaning by the nitrogen jet, and $\mathbf{f}$ after cleaning by the $\mathrm{CO}_{2}$ snow jet

The effectiveness of each cleaning method was characterised by the total colour change $(\Delta E)$. Due to minor changes of $a^{*}$ and $b^{*}$, parameter $L^{*}$ was used to evaluate the effectiveness $(\eta)(\%)$. The results are shown in Table 5.

As can be seen, the efficiency of different cleaning methods is comparable. It could be explained that most of the darkening is caused by the larger particles, which are most easily removed by any cleaning technique. This would also correspond to the higher efficiency of cleaning of smooth surface of the Holmen paper. As can be seen from Fig. 12 the lower efficiencies coincide with the observed alteration of the surface, such as smearing of impurities or residues of cleaning material left on the surface (e.g., Fig. 12a). Further, changes of the surface structure can be seen after the Faber Castell application (Fig. 12d). The $\mathrm{CO}_{2}$ snow jet cleaning was effective in the lower layers of the paper surface, including interfiber spaces (Fig. 12f), whereas the nitrogen jet had lower efficiency (Fig. 12e). The mechanical cleaning methods were not effective at the lower fibers and interfiber spaces (Fig. 12a-d).

Possible long-term effects of cleaning were assessed using accelerated thermal aging of Ivory Black and clean samples. The effects of the aging were examined microscopically and analysed according to the colour change, the folding endurance, and the $\mathrm{pH}$ value of the coldwater extract of the paper.

The SEM analyse did not showed any substantial changes of the surface morphology after the aging. The colour change measurements revealed mainly darkening and yellowing of the Holmen paper (Table 6). However, the results of cleaned samples and reference were comparable. The colour change of the Watman paper was negligible. The folding endurance and $\mathrm{pH}$ value remained practically unchanged. Although the results did not show any substantial changes of paper properties after the accelerated aging, the potentional risk of degradation caused by remains of the cleaning material should be considered.

\section{Model}

This study examined the removal via $\mathrm{CO}_{2}$ snow and nitrogen jets of contaminant particles deposited on paper surfaces. The purpose was to find out if these techniques could be used for cleaning of surfaces of historical documents contaminated by fine dust. Both methods were 

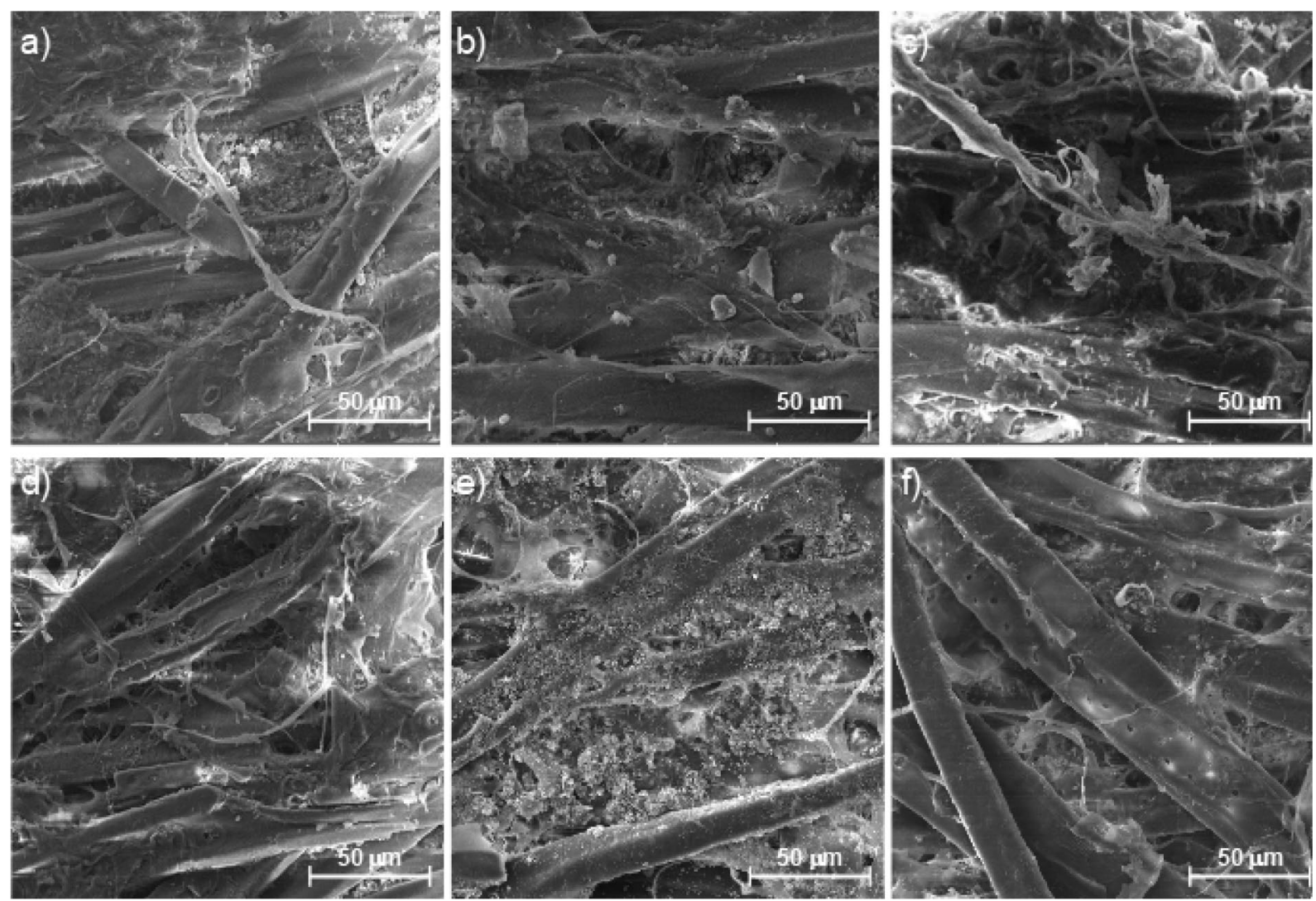

Fig. 11 Example of the Holmen paper contaminated by the Ashrae Dust cleaned by a Wallmaster, b Wishab, c Groom/Stick, d Faber Castell, e nitrogen jet, and $\mathbf{f} \mathrm{CO}_{2}$ snow jet (see the clean Holmen paper in Fig. 1)

Table 5 Effectiveness ( $\eta$ ) of different cleaning methods in \% ( \pm SD)

\begin{tabular}{|c|c|c|c|c|c|c|}
\hline & Wallmaster & Wishab & Groom/Stick & Faber Castell & $\mathrm{N}_{2}$ jet & $\mathrm{CO}_{2}$ snow jet \\
\hline \multicolumn{7}{|l|}{ Ashrae Dust } \\
\hline Whatman & $14( \pm 3)$ & $33( \pm 7)$ & $37( \pm 8)$ & $75( \pm 16)$ & $34( \pm 7)$ & $38( \pm 8)$ \\
\hline Holmen & $62( \pm 13)$ & $68( \pm 14)$ & $95( \pm 17)$ & $78( \pm 15)$ & $52( \pm 11)$ & $82( \pm 15)$ \\
\hline \multicolumn{7}{|l|}{ Ivory Black } \\
\hline Whatman & $52( \pm 3)$ & $17( \pm 2)$ & $97( \pm 7)$ & $94( \pm 7)$ & $47( \pm 4)$ & $56( \pm 4)$ \\
\hline Holmen & $59( \pm 4)$ & $80( \pm 4)$ & $97( \pm 5)$ & $92( \pm 6)$ & $68( \pm 5)$ & $88( \pm 6)$ \\
\hline \multicolumn{7}{|l|}{ Library Dust } \\
\hline Whatman & $100( \pm 28)$ & $94( \pm 27)$ & $93( \pm 26)$ & $76( \pm 24)$ & $22( \pm 7)$ & $55( \pm 18)$ \\
\hline Holmen & $75( \pm 25)$ & $79( \pm 25)$ & $75( \pm 23)$ & $87( \pm 24)$ & $57( \pm 19)$ & $54( \pm 17)$ \\
\hline
\end{tabular}

tested experimentally evaluating the efficiency of fine particle removal and no evident damage to the surface as criteria. In order to assess the suitable operating conditions, the experimental results were compared with the theoretical calculations of removal and adhesion forces at the moment of separation. This included the van der Waals force as the force of adhesion, and the Stokes drag force and the impact force due to collision with the dry ice particles as the removal forces. The calculations were performed for PM1 $(0.1-1 \mu \mathrm{m})$, monodispersed ammonium sulphate $(0.2 \mu \mathrm{m})$ and soot $(0.1 \mu \mathrm{m})$ contaminant particles, and dry ice particles ranging from $0.2 \mu \mathrm{m}$ to $6 \mu \mathrm{m}$, considering geometric restriction for particles impacting at angle $45^{\circ} \mathrm{D}_{\text {imp }} \leq 5.82 \mathrm{D}_{\text {dep }}$ [45]. The dry ice particles with sizes $0.5-11 \mu \mathrm{m}$ produced by expanding liquid carbon dioxide were measured by Lin et al. [46], 

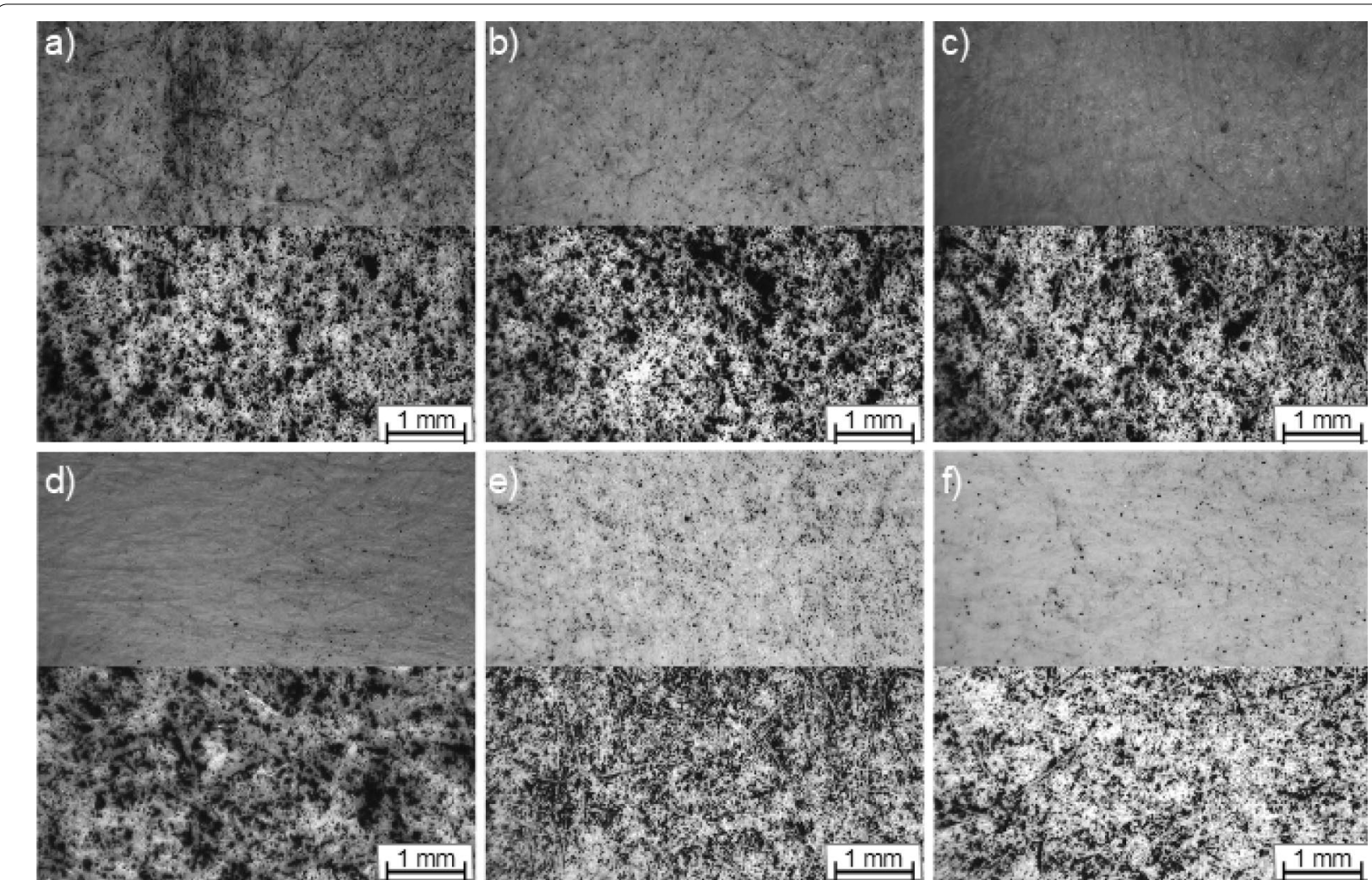

Fig. 12 Examples of 3D optical micrographs of the Holmen paper contaminated by the Ivory Black (lower: before cleaning; upper: after cleaning) cleaned by a Wallmaster, b Wishab, c Groom/Stick, d Faber Castell, e nitrogen jet, and $\mathbf{f} \mathrm{CO}_{2}$ snow jet

Table 6 Colour change of the Holmen paper caused by the accelerated aging ( \pm SD)

\begin{tabular}{llllll}
\hline & $\boldsymbol{\Delta} \boldsymbol{L}^{*}$ & $\boldsymbol{\Delta \boldsymbol { a } ^ { * }}$ & $\boldsymbol{\Delta \boldsymbol { b } ^ { * }}$ & $\boldsymbol{\Delta \boldsymbol { E } ^ { * }}$ & $\boldsymbol{\Delta E \mathbf { 2 0 0 0 }}$ \\
\hline Wallmaster & $3.88( \pm 0.14)$ & $-1.53( \pm 0.08)$ & $0.55( \pm 0.06)$ & $4.21( \pm 0.15)$ & $2.69( \pm 0.14)$ \\
Wishab & $3.88( \pm 0.20)$ & $-1.37( \pm 0.21)$ & $0.50( \pm 0.06)$ & $4.15(0.24)$ & $2.63( \pm 0.21)$ \\
Groom/Stick & $3.88(0.15)$ & $-1.52( \pm 0.13)$ & $0.59( \pm 0.07)$ & $4.21( \pm 0.15)$ & $2.69( \pm 0.15)$ \\
Faber Castell & $3.81( \pm 0.14)$ & $-1.49( \pm 0.14)$ & $0.57( \pm 0.08)$ & $4.14( \pm 0.14)$ & $2.65( \pm 0.15)$ \\
Nitrogen jet & $3.69( \pm 0.19)$ & $-1.64( \pm 0.22)$ & $0.67( \pm 0.07)$ & $4.10( \pm 0.15)$ & $2.68( \pm 0.17)$ \\
$C_{2}$ snow jet & $3.87( \pm 0.15)$ & $-1.74( \pm 0.16)$ & $0.71( \pm 0.09)$ & $4.30( \pm 0.13)$ & $2.83( \pm 0.15)$ \\
Reference & $3.95( \pm 0.10)$ & $-1.62( \pm 0.11)$ & $0.70( \pm 0.08)$ & $4.33( \pm 0.12)$ & $2.85( \pm 0.13)$ \\
\hline
\end{tabular}

the size $0.2 \mu \mathrm{m}$ was considered assuming dry ice particles can also evaporate.

\section{The nitrogen jet particle removal}

There are two main forces considered in the aerodynamic cleaning the van der Waals adhesion force binding particles to a surface, and the Stokes drag force caused by the gas flow which acts as the removal force. The van der Waals force is proportional to the contaminant particle diameter $d$, while the Stokes drag force is proportional to the $\sim d^{2}[47]$ and hence decreases more rapidly as the contaminant particle becomes smaller. As a result, the Stokes drag is insufficient in the submicron-size particles removal (Fig. 14). This conciulsion agrees quite well with the results of submicron particle cleaning which were almost ineffective (Fig. 9).

Moreover, Fig. 13 also revealed that for coarse particles, the drag forces can overcome the adhesion forces. This corresponds well with results of coarse particles cleaning (Ashrae Dust, Ivory Black, and Library Dust) which showed comparable efficiencies for both the nitrogen and the $\mathrm{CO}_{2}$ snow jets (Table 4) indicating that the drag force 


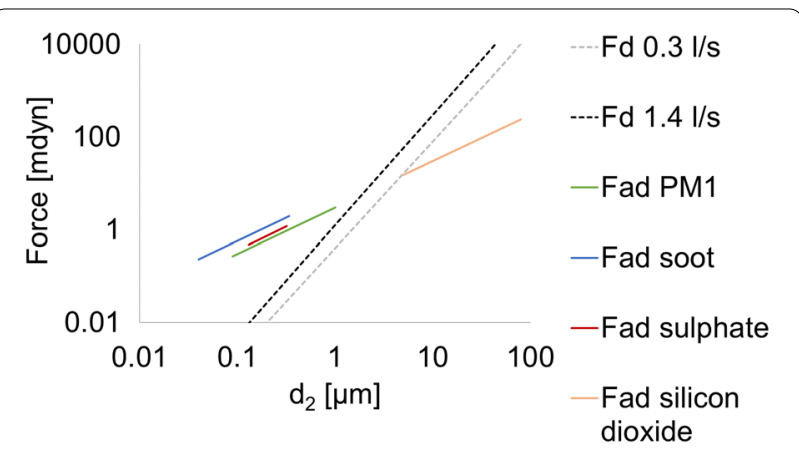

Fig. 13 Comparison of drag forces $\left(F_{d}\right)$ and adhesion forces $\left(F_{a d}\right)$ for nitrogen jet cleaning of PM1, sulphate, soot, and silicon dioxide from Whatman paper in relation to the contaminant particle diameter $\left(d_{2}\right)$ (adhesion forces are shown in corresponding size fractions)

can cause particle removal. Silicon dioxide (size fraction 5-80 $\mu \mathrm{m}$ ) was used for modelling, because it represents approx. $70 \%$ of the Ashrae Dust [34].

\section{The $\mathrm{CO}_{2}$ snow jet particle removal}

Figure $14 \mathrm{a}, \mathrm{b}$ shows conditions modelled for the modesizes of PM1 and ammonium sulphate particles. As these particles were mostly irregular, we utilized the impact sliding mechanism: the contaminant particle will be removed if the ratio of forces $r *$ is higher than 1 (see Additional file 1). The results revealed that the cleaning efficiency grows with the nitrogen flow rate and that PM1 particles can be at least partially removed under all tested operation conditions. For the sulphate particles the flow rate of $0.3 \mathrm{l} / \mathrm{s}$ is ineffective, whereas, $0.6 \mathrm{l} / \mathrm{s}$ can partially remove contaminants, and $1.4 \mathrm{l} / \mathrm{s}$ has even higher cleaning efficiency. These findings correspond well with results of submicron-size particle cleaning experiments (Fig. 8).
Finally, it is important to bear in mind that the experiments performed with nitrogen and dry ice jet cleaning of paper surfaces were evaluated using the simple theoretical calculation of adhesion and removal forces in order to delineate the processes involved. Certainly, the modelled situations differ from real conditions (e.g., assuming only spherical particles deposited on flat smooth surface compared to irregular particles deposited on and into fibrous surface and many other simplifications) and there are many different parameters that affect the flow-driven particle removal [48] that should be considered. Nevertheless, these findings could help to better understand the principles of both methods and to attain further knowledge for application.

\section{Cleaning of archival paper}

The methods were verified using the cleaning of archival paper. The sheet was identified as a wood-based paper. Microscopic investigation and colour change analysis of the paper surface were performed before and after cleaning. The microscopic examination did show any significant changes in the surface structure (Fig. 15). The analyses also revealed negligible removal efficiency of the nitrogen jet, whereas after the $\mathrm{CO}_{2}$ snow jet cleaning the amount of contaminant particles was significantly reduced.

The total colour difference $(\Delta E)$ after nitrogen jet and $\mathrm{CO}_{2}$ snow jet treatment was 0.52 and 6.18 , respectively. This shows the negligible effect of the nitrogen jet, which is not perceptible by an observer $(\Delta E<1.00)$. For comparison $\triangle E 2000$ after nitrogen jet and $\mathrm{CO}_{2}$ snow jet treatment was 0.36 and 5.30, respectively. However, after the $\mathrm{CO}_{2}$ snow jet cleaning, the difference exceeded the limit $\Delta E=5.00$ which indicates that an

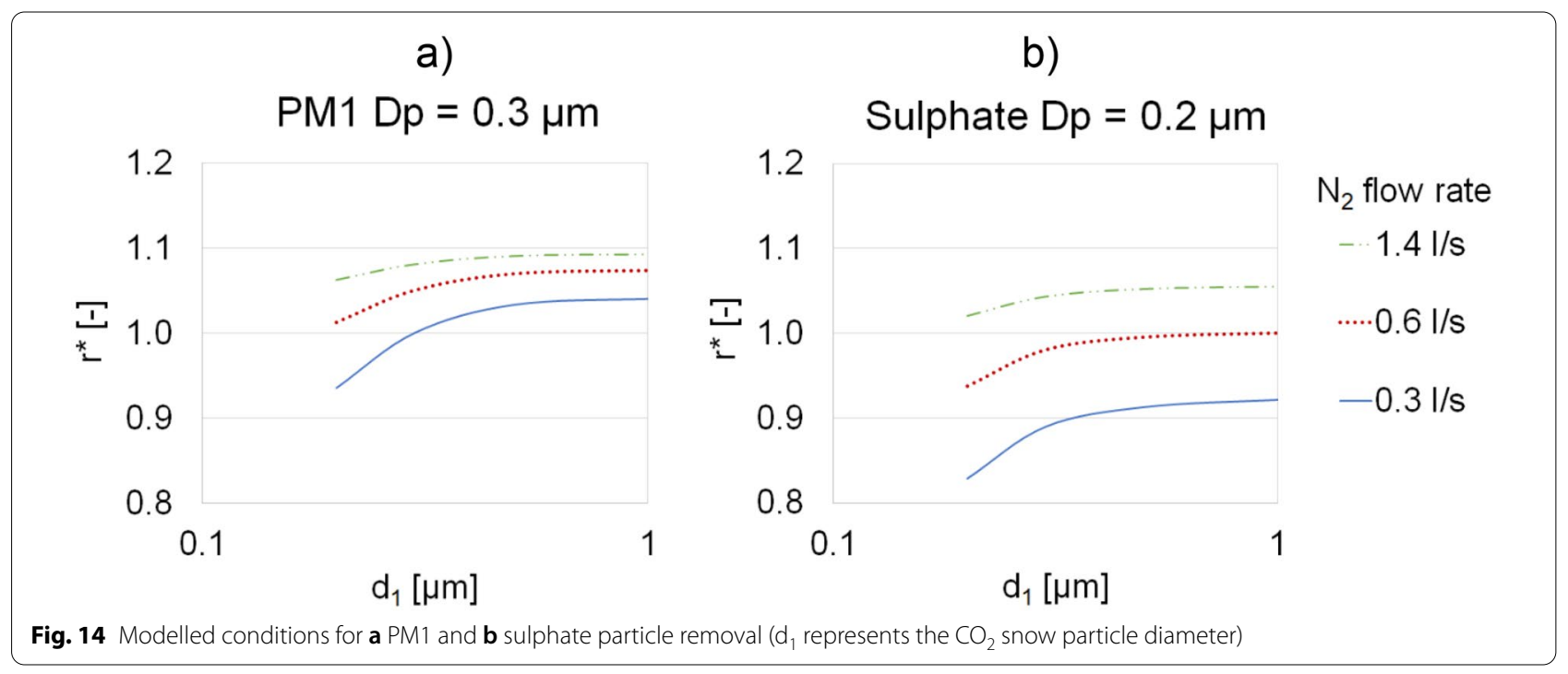



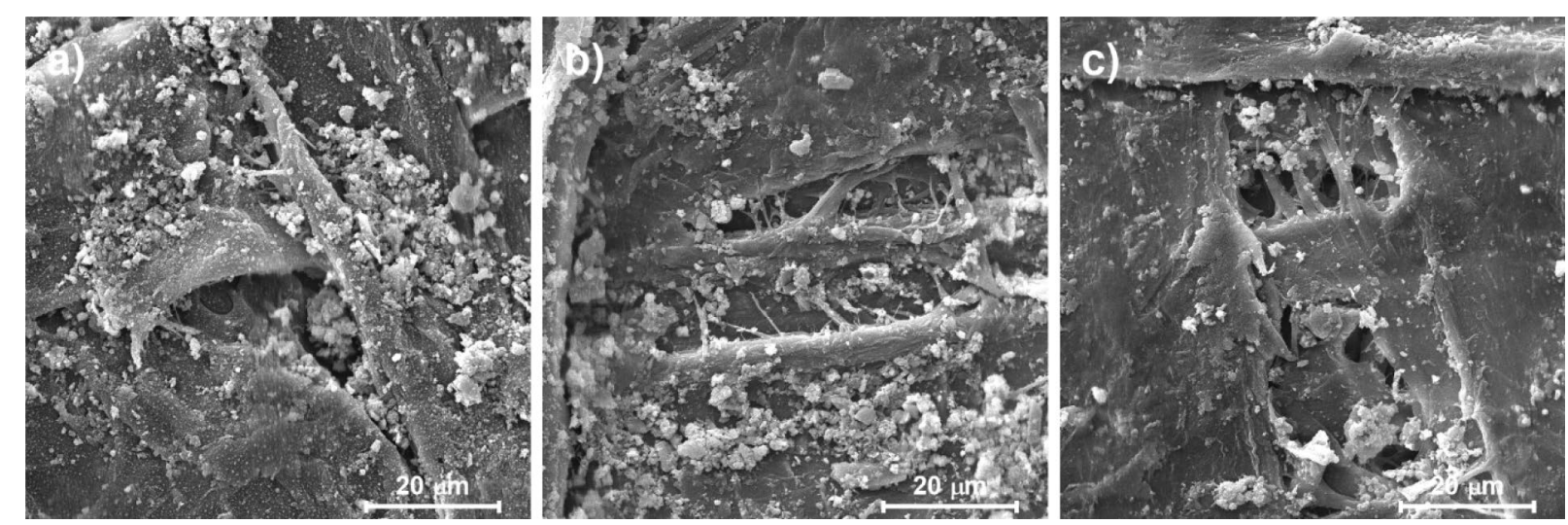

Fig. 15 The archival paper a before cleaning, $\mathbf{b}$ after nitrogen jet cleaning, and $\mathbf{c}$ after $\mathrm{CO}_{2}$ snow jet cleaning

observer could notice two different colours [42]. This corresponds well with the results of test samples cleaning and modelling. However, particular materials which are partially damaged or degraded require individual evaluation and preliminary tests before the treatment.

\section{Conclusions}

The removal via the $\mathrm{CO}_{2}$ snow jet and the nitrogen jet of dust particles deposited on paper surface has been investigated. The measurements included characterization of the $\mathrm{CO}_{2}$ snow jet properties, examination of the possible adverse effects and evaluation of the cleaning effectiveness. The results were compared with the nitrogen jet cleaning and the dry cleaning by commercial cleaning materials. Based on results the following conclusions are drawn:

- The $\mathrm{CO}_{2}$ snow jet cleaning is effective in the removal of particles from paper surfaces including the submicron-sized particles ingrained in the surface.

- This method has not caused any observable damage of surface and any substantial change of mechanical and optical properties of mechanical pulp paper.

- The $\mathrm{CO}_{2}$ snow jet has been generated by the expansion of liquid carbon dioxide using a co-axial nozzle which supported the flow of nitrogen. The jet properties and hence the effectiveness of cleaning could be easily controlled by altering the nitrogen flow rate.

- The results of the $\mathrm{CO}_{2}$ snow cleaning compared with the mechanical dry cleaning showed similar effectiveness without any adverse effects on the paper surface.

- The $\mathrm{CO}_{2}$ snow technique is suitable for the cleaning of common types of paper materials.
Finally, it should be mentioned that there are also other properties that were not examined but should be considered: the $\mathrm{CO}_{2}$ snow cleaning is fast (comparable or faster than traditional dry cleaning methods), it does not produce any residue except for the removed contaminants, it can be used for cleaning small samples, it could be used also for the cleaning of less accessible surfaces e.g. inside headband or at joint area of books), and the equipment does not need much space. On the other hand, an initial investment to the $\mathrm{CO}_{2}$ snow jet is essential (in the order of thousands of Euro). However, the operating costs are relatively low and cover mostly only the $\mathrm{CO} 2$ and the carrier gas consumption.

\section{Supplementary Information}

The online version contains supplementary material available at https://doi. org/10.1186/s40494-021-00622-0.

Additional file 1: Table S1. List of material properties used for modelling.

\section{Acknowledgements}

Not applicable.

\section{Authors' contributions}

LM performed the nitrogen jet and $\mathrm{CO}_{2}$ snow jet cleaning, characterised the jets properties, and was a major contributor in writing the manuscript. JS supervised the measurements and was a major contributor in writing the manuscript. PV supervised the samples preparation and the analysis. JN analysed the paper microscopically, by the colour, the folding endurance, and the $\mathrm{pH}$ value of the cold-water extract, and supervised the samples preparation. MS cooperated in the samples preparation and the analysis. DN cooperated in the samples preparation and the analysis. VJ performed the SEM analysis. $\mathrm{JO}$ cooperated in the cleaning. LO cooperated in the cleaning. TK cooperated in the samples preparation and the analysis. KK cooperated in the samples preparation and the analysis. PS performed the PIV analysis. All authors read and approved the final manuscript.

\section{Funding}

The work was supported by the Ministry of Culture of the Czech Republic under Grant DG18P02OVV048. 


\section{Availability of data and materials}

The datasets used and/or analysed during the current study are available from the corresponding author on reasonable request.

\section{Declarations}

\section{Competing interests}

The authors declare that they have no competing interests.

\section{Author details}

${ }^{1}$ Institute of Chemical Process Fundamentals, The Czech Academy of Sciences, Rozvojová 135, 16502 Prague 6, Czech Republic. ${ }^{2}$ National Library of the Czech Republic, Klementinum 19, 11000 Prague 1, Czech Republic.

\section{Received: 14 June 2021 Accepted: 25 October 2021}

Published online: 07 November 2021

\section{References}

1. Lloyd $\mathrm{H}$, et al. The effects of visitor activity on dust in historic collections. Conservator. 2002:26:72-84.

2. Lloyd H, et al. Dust in historic libraries. In: Borchersen T, Padfield K, editors., et al., Museum microclimates. Copenhagen: The National Museum of Denmark; 2007. p. 135-44

3. Thickett D, et al. Libraries and archives in historic buildings. In: Borchersen T, Padfield K, editors., et al., Museum microclimates. Copenhagen: National Museum of Denmark; 2007. p. 145-55.

4. Chatoutsidou SE, et al. Modeling of the aerosol infiltration characteristics in a cultural heritage building: The Baroque Library Hall in Prague. Build Environ. 2015;89:253-63.

5. Mašková L, et al. Contribution of visitors to the indoor PM in the National Library in Prague, Czech Republic. Aerosol Air Qual Res. 2016;16(7):1713-21.

6. Mašková $\mathrm{L}$, et al. Characterisation of particulate matter in different types of archives. Atmos Environ. 2015;107:217-24.

7. Mašková $L$, et al. Air quality in archives housed in historic buildings: assessment of concentration of indoor particles of outdoor origin. Build Environ. 2020;180:100724.

8. Mašková L, et al. Characterization of indoor air quality in different archives-possible implications for books and manuscripts. Build Environ. 2017:120:77-84

9. López-Aparicio $S$, et al. Relationship of indoor and outdoor air pollutants in a naturally ventilated historical building envelope. Build Environ. 2011;46(7):1460-8.

10. Vichi $F$, et al. Simultaneous measurement of nitrous acid, nitric acid, and nitrogen dioxide by means of a novel multipollutant diffusive sampler in libraries and archives. Herit Sci. 2016;4(4):1-8.

11. Grau-Bové J, Strlič M. Fine particulate matter in indoor cultural heritage: a literature review. Herit Sci. 2013;1(8):1-17.

12. Smolík J, et al. Deposition of suspended fine particulate matter in a library. Herit Sci. 2013;1(7):1-5.

13. Hatchfield PB. Pollutants in the museum environment, practical strategies for problem solving in designm exhibition and storage. London: Archetype Publications; 2002

14. Tétreault J. Airborne pollutants in museums, galleries, and archives: risk assessment, control strategies and preservation management. Ottawa: Canadian Conservation Institute; 2003.

15. Bartl B, et al. The effect of dust particles on cellulose degradation. Stud Conserv. 2016;61(4):203-8.

16. Bendix C, Walker A. Cleaning books and documents. London: Preservation Advisory Centre; 2011.

17. Zidan Y, et al. A comparative study to evaluate conventional and nonconventional cleaning treatments of cellulosic paper supports. Mediter Archaeol Archaeom. 2017;17(3):337-53.

18. Estabrook E. Considerations of the effect of erasers on cotton fabric. J Am Inst Conserv. 1989;28:79-96.

19. Pearlstein EJ, et al. Effects of eraser treatment on paper. J Am Inst Conserv. 1982;22(1):1-12.
20. Silverman R. Fire and ice: a soot removal technique using dry ice blasting. Int Preserv News. 2009;39:1-9.

21. Sherman R. Chapter 3 carbon dioxide snow cleaning applications. In: Mittal R, Kholi KL, editors. Developments in surface contamination and cleaning: applications of cleaning techniques, vol. 11. Amsterdam: Elsevier; 2019. p. 97-115.

22. Sherman $\mathrm{R}$, et al. Dry surface cleaning using $\mathrm{CO}_{2}$ snow. J Vac Sci Technol B. 1991;9(4):1970-7.

23. Shockey LH. Blow it off: moving beyond compressed air with carbon dioxide snow. Objects Spec Group Postprints. 2009;16:13-24.

24. Odegaard N. Investigations using liquid $\mathrm{CO}_{2}$ to clean textiles and basketry. Conference ice cold: solid carbon dioxide cleaning. Smithsonian American Art Museum. 2016. https://www.youtube.com/watch?v= P4gOPpNgdWQ. Accessed 6 Aug 2020.

25. Tsang J, Babo S. Soot removal from acrylic emulsion paint test panels: a study of dry and non-contact cleaning, modern materials and contemporary art. Lisbon: ICOM CC; 2011. p. 1-9.

26. Součková M, et al. Evaluation methods of effect of cleaning techniques on library collagen materials. Proc SPIE Int Soc Opt Eng. 2019:11058:110581l.

27. Silverman R, Irwin S. Fire and ice revisited: a comparison of two soot removal techniques for book. Int Preserv News. 2009;49:31-5.

28. van der Molen Rl, et al. Dry ice blasting for the conservation cleaning of metals. In: Mardikian P, et al., editors. Metal 2010: Proceedings of the Interim Meeting of the ICOM-CC Metal Working Group. Clemson: Clemson University; 2010. p. 96-103.

29. Cutulle C, Kim S, et al. Dry ice blasting in the conservation of metals: a technical assessment as a conservation technique and practical application in the removal of surface coatings. In: Hamilton E, et al., editors. Objects specialty group postprints, vol. 22. Washington: The American Institute for Conservation of Historic \& Artistic Works; 2015. p. 77-100.

30. Taumer R, et al. Qualification of local advanced cryogenic cleaning technology for $14 \mathrm{~nm}$ photomask fabrication. Proceedings Conference Photomask Technology 2014. SPIE 9235. Monterey, California; 2014. p. 923525.

31. Fellers C, et al. Ageing/degradation of paper a literature survey. Stockholm: FoU-projektet for papperskonservering; 1989. (Report No. 1E ISSN 0284-5636).

32. Jackson DP. Dense fluid spray cleaning method and apparatus. US Patent US5725154A, 10 June 1998

33. Zíková N, et al. Size-resolved penetration through high-efficiency filter media typically used for aerosol sampling. Aerosol Sci Technol. 2015:49:239-49.

34. PTI Powder Technology Inc. ASHRAE Test Dust \#1 Per ANSI/ASHRAE 52.1 and 52.2. [Online] [Ref.: 6/8/2021]. https://www.powdertechnologyinc. com/product/ashrae-test-dust-1/.

35. Ševců R, et al. Specializovaná databáze pigmentů a barviv. Prague: Národní galerie v Praze; 2017.

36. Luo MR, et al. The development of the CIE 2000 colour-difference formula: CIEDE2000. Color Res Appl. 2001;26(5):340-50.

37. ISO 5626. Paper-Determination of folding endurance. Geneva: International Organization for Standardization; 1993.

38. ISO 5630-1. Paper and board-accelerated ageing-part 1: dry heat treatment at 105 degrees C. Geneva: International Organization for Standardization; 1991.

39. Kwak S. Computational analysis for sublimation enhanced heat transfer of $\mathrm{CO}_{2}$ jet impingement cooling. Master's Thesis. Department of Mechanical Engineering, Graduate School of UNIST, Ulsan; 2016.

40. Zervos S, Moropoulou A. Methodology and criteria for the evaluation of paper conservation interventions, Literature review. Restaurator. 2006;27(4):219-27.

41. Zervos S. Evaluating treatments of paper using statistically valid test methods. Part II: experimental setup and protocol. Restaurator. 2007:28(4):256-88.

42. Mokrzycki WS, Tatol M. Color difference $\triangle E$-a survey. Mach Graph Vis. 2011:20(4):383-411.

43. Technical Association of the Pulp and Paper Industry (TAPPI). Accelerated pollutant aging of printing and writing paper by pollution chamber exposure apparatus. Peachtree Corners, GA; 2008. T 572 sp-08. 
44. Technical Association of the Pulp and Paper Industry (TAPPI). Accelerated pollutant aging of printing and writing paper by pollution chamber exposure apparatus. Peachtree Corners, GA; 2013. T 572 sp-13.

45. Liu YH, et al. Effect of particle impact on surface cleaning using dry ice jet. Aerosol Sci Technol. 2011:45(12):1519-27.

46. Lin TC, et al. Effect of superheat on characteristics of flashing spray and snow particles produced by expanding liquid carbon dioxide. J Aerosol Sci. 2013;61:27-35.

47. Hinds WC. Aerosol Technology: properties, behavior, and measurement of airborne particles. 2nd ed. Chichester: Wiley; 1999.
48. Kesavan J, et al. Experimental and computational study of reaerosolization of 1 to 5 Mm PSL microspheres using jet impingement. Aerosol Sci Technol. 2017;51(3):377-87.

\section{Publisher's Note}

Springer Nature remains neutral with regard to jurisdictional claims in published maps and institutional affiliations.

\section{Submit your manuscript to a SpringerOpen ${ }^{\circ}$ journal and benefit from:}

- Convenient online submission

- Rigorous peer review

- Open access: articles freely available online

- High visibility within the field

- Retaining the copyright to your article

Submit your next manuscript at $\boldsymbol{\nabla}$ springeropen.com 